\title{
IMPLEMENTATION OF ISO 22000 IN ROMANIAN COMPANIES: MOTIVATIONS, DIFFICULTIES AND KEY BENEFITS
}

\author{
Carmen Păunescu ${ }^{1 *}$, Ruxandra Argatu ${ }^{2}$ and Miruna Lungu ${ }^{3}$ \\ ${ }^{1223)}$ The Bucharest University of Economic Studies, Romania
}

Please cite this article as:

Păunescu, C., Argatu, R. and Lungu, M., 2018. Implementation of ISO 22000 in Romanian Companies: Motivations, Difficulties and Key Benefits. Amfiteatru Economic, 20(47), pp. 30-45.

\section{Article History}

Received: 30 September 2017

Revised: 20 October 2017

Accepted: 22 November 2017

\begin{abstract}
The development of well-designed food safety management systems that take into consideration the potential risks and threats to an organization and their associated impacts to business operations should be a key goal for each organization operating in the food supply chain. This study provides quantitative empirical evidence about the motivations for implementing a food safety management system based on ISO 22000. By employing factor analysis and multiple linear regression, it analyses the benefits that the ISO 22000 certified companies gained through certification, as well as the main constraints that may prevent the adoption of the standard in the food industry. The survey is based on a sample of Romanian companies distributed at all levels of the food chain, but mainly at the production level. While there exist external pressures that lead companies to adopt a food safety management system based on ISO 22000, the motivations that are most relevant in this decision are generally internal in nature. The results of our study identify three major benefits of ISO 22000 certification: food safety improvement and provision of safer products, reduction of illness and other risks arising from food and improvement of consumers' confidence. Also, it points out three constraints limiting the dissemination and use of ISO 22000: employees' qualification, costs associated with food safety management system implementation and legal requirements.
\end{abstract}

Keywords: food safety management system, ISO 22000, Romanian companies, food industry, factor analysis, multiple regression.

JEL Classification: L15, M19, Q18, L66.

*Corresponding author, Carmen Păunescu - carmen.paunescu@ ase.ro 


\section{Introduction}

Food safety represents a fundamental public health concern for every actor involvedalong the food supply chain.Nowadays, the need for a consistent approach to food safety management along the whole food supply chain, from the farm to the table, is vital. A wide number of food borne hazards pose risks and threats to health and raise barriers to global trade in foods (Soman and Raman, 2016). The global public health challenges as well as the more stringent government regulations and the increasing demands from the customers concerning the food safety take more and more food companies to seek better and safer production systems or service delivery.Beyond complying with basic food regulations and following acceptable workplace practices, more organisations are deciding to develop a comprehensive food safety management system, which is critical to the success of the business, either it operates in food production, storage, packaging or preparation (Mensah and Julien, 2011; Escanciano and Santos-Vijande, 2014b). An efficient food safety management system helps the company to protect its competitive market place, customers and the community, guaranteeing continuous prevention of food borne illnesses, and the promotion of safe to eat foods. Also, to gain more customers' confidence and increase market reputation, more organisations are choosing to have their food safety management systems certified based on an internationally recognized standard and practices. As such, the international standard ISO 22000:2005 Food safety management systems Requirements for any organization in the food chain was created to help organizations identify and control food safety hazards by developing and adopting a food safety management system (ISO, 2005).

The current study aims to identify the motivations of Romanian companies to implement a food safety management system based on the international standard ISO 22000, the main constraints that may prevent the adoption of the standard in the food industry,and the key benefits that the ISO 22000 certified companies gained through certification. The paper provides quantitative empirical evidence for Romanian companies which operate in the food industry, interested in adopting the ISO 22000 model of food safety management. The paper is structured in three main parts. In the first section, based on the literature review in the field, it discusses the main challenges regarding the food safety management system development and adoption. Then, the research methodology is explained, including sampling, research tool and methods of analysis. Finally, a section of results and discussion follows, based on the views expressed by the sample companies and in connection with the findings from the literature reviewed, followed by a section of conclusion.

\section{Literature review on food safety management systems}

\subsection{What is a food safety management system?}

A Food Safety Management System (FSMS) is a vital part of any modern food business. Organizations in the food chain need to demonstrate their ability to control food safety hazards in order to ensure that food is safe at the time of human consumption. A wellestablished FSMS allows for identifying risks to food safety and detailing how they are monitored and controlled in the organization (Smith, Jackson-Smithand Politowski, 2007; Soares, Vicenteand Martins, 2016). Therefore, the international standard ISO 22000 specifies basic requirements for a food safety management system, and provides a systematic methodology for analysing food processes, determining the possible hazards, 
and designating the critical control points and risks. These steps are necessary to prevent unsafe food from reaching the consumer (Sheps, 2007; Arvanitoyannis, 2009). This approach helps to minimize the risk of food poisoning and to maintain food safe for consumption. A well-designed FSMS with appropriate control measures can help food companies comply with food government regulations and ensure that food prepared for sale is hygienic and safe for consumers.A food safety management system in conformity with ISO 22000 means that the company has a documented system in place and fully implemented throughout its facility that includes:

- Effective prerequisite programs in place to ensure a clean sanitary environment. These are programs used to control the likelihood of introducing contamination through the work environment(Afoakwa et al., 2013), such as: construction and layout of building, layout of premises and workspace, utilities - air, water, energy, waste disposal, equipment suitability, cleaning and maintenance, management of purchased material, measures for prevention of cross contamination, cleaning and sanitizing, pest control, personnel hygiene and employee facilities, rework, product recall procedures, warehousing.

- A Hazard Analysis and Critical Control Plan (HACCP) developed to identify, prevent and eliminate food safety hazards. This includes biological, chemical or physical hazards.

- Established documented food safety management system processes to manage food safety throughout the organization.

Becoming certified to ISO 22000 allows a company to show its customers that it has an effective food safety management system in place (Zorpas and Tzia, 2008), whichguarantees safe food for consumption. This is becoming more and more important as customers demand safe food and food processors require that ingredients obtained from their suppliers are safe (Păunescu, 2017).

\subsection{Motivations for the adoption of the ISO 22000 food safety management system}

According to Escanciano and Santos-Vijande (2014a) the reasons that are most determinant in the decision to adopt an ISO 22000 food safety management system are internal in nature, specifically the desire to improve efficiency, productivity and quality. This point of view is supported by Weyandt et al. (2011) who consider that the implementation of ISO 22000 has a series of specific reasons behind. The authors claim that the motivation factors which drive the idea of adopting the standard arise from different sources, all being internal in nature. These are: the need of securing a leverage on the market, strengthening the customer's confidence level, adding value to the organization and improving the management system. Related to the customers' confidence, Stranieri, Cavaliere and Banterle (2017) confirm that the organizations which possess an ISO certification are perceived as having less risky products. Teixeira and Sampaio (2013) strengthen this opinion, as they claim that assuring customers' confidence is one of the top motivational factors in the adoption of ISO 22000.

Analysing an ISO ranking conducted by Massoud et al. (2010), ISO 22000 is one of the most popular ISO standards, having the highest level of priority. The wide spread of the ISO 22000 represents a motivation for an organization to market differentiation as per Teixeira and Sampaio (2013). Further on, Macheka et al. (2013) highlight also market differentiation as one of the motivation key points for implementing a food safety standard. By embracing a food safety certification, the organization is positively influenced to increase the quality of its products. This reasoning confirms that the organization is 
committed to deliver the best to its customers, having a superior level of customer care. Mensah and Julien (2011) emphasize that many organizations orientate towards an ISO certification to influence their image on the market or to be aligned with their competitors. Given the context of a competitive market, the adoption of ISO 22000 by top players might push the other players to update this strategy regarding safety certification.

Stranieri, Cavaliere and Banterle (2017) break down the types of motivation into categories. These claim that the drivers of motivation in implementing the ISO 22000 standard are connected to confidence, profitability, regulation and supply chain. Considering the profitability motivation factor, the organization takes into account the financial impact generated by the ISO adoption, as it strives to increase profit and continuously reinvest it, and, therefore, make the company more sustainable. Focusing on efficiency as a reason in choosing an ISO standard as a motivation factor, we can relate to Wognum et al. (2011). The authors emphasize that the implementation and certification to ISO 22000 standard includes a set of standardized policies which lead to transparency between different levels and actors of the food supply chain and a better overview of cost allocation resource. This incentive represents a motivational opportunity for the organization to deliver value to the customers and at the same time to reduce costs. In their research, Mensah and Julien (2011) support the idea that ISO 22000 contributes significantly to cost reduction within an organization. Regarding efficiency as a contributor in following the ISO 22000, Silva, Fonseca and Sousa (2016) view it as a way of improving the level of efficiency and better control the processes.

Another motivational factor in adopting ISO 22000 refers to the legal advantage offered by the certification. As per Lokunarangodage, Wickramasinghe and Ranaweera (2016) the standard is aligned with the current European legislation. In the light of an open market, through the adoption of an international regulation the organization can have a wider access to international markets. As a consequence, the organization can expand its operation, by having an aligned international way of doing business.

\subsection{Benefits and constraints to the implementation of an ISO 22000 food safety management system}

The adoption of the ISO 22000 standard brings a large variety of benefits for the companies that choose to embrace it. Thus, according to Herath and Henson (2006) such advantages are represented by the product quality enhancement and of the production processes, which can be further translated into an advancement of the company's market position and a better approach of threats coming from the market which the company serves. Moreover, ISO 22000 also helps companies to better adapt to the legal framework established in order to ensure food safety (Mensah and Julien, 2011). This food safety management system does not only improve the company's performance in terms of product and production process quality, but it also contributes to the obtainment of a transparent and efficient communication between the company and its stakeholders (Mamalis, Kafetzopoulos and Aggelopoulos, 2009). More precisely, by implementing ISO 22000, companies can clear off possible dangers related to food through using a standardized language that makes an effective link between them and their stakeholders: customers, suppliers, distributors and health institutions (Bilalis et al., 2009). However, large firms are more aware of, and able to deal with, risks from a greater range of contaminants, and therefore are able to adopt more stringent schemes regarding food safety management than SMEs (Kök, 2009). 
Apart from that, Bilalis et al. (2009) also claim that the implementation of ISO 22000 is a driver for reaching continuous improvement, due to the fact that it is further linked to the PDCA (plan, do, check, act) system. Thus, the safety management system minimizes the probability of customer dissatisfaction and product flaws. Ahmed, Saeed and Hussien (2013) demonstrate that the implementation of ISO 22000 speeds and simplifies processes, increases efficiency and reduces costs. Also, it improves food safety and hazard control. Another benefit brought by the implementation of ISO 22000 and concerning the customer relationship area is the fact that companies which have an ISO 22000 certification are more credible towards their customers (Faergemand, 2008; Uyar et al., 2012). Also, Keran et al. (2008) found that the implementation of the ISO 22000 standard provided better safety of the final products. This was due to the control of suppliers of all raw materials, as well as the traceability.

Cost saving possibilities are also enabled through the implementation of ISO 22000 Mensah and Julien (2011) underline the time and cost efficiency provided by the usage of the ISO certification standard, as the ISO 22000 audit can be undertaken by combining the application of other standards' audit. According to practical research conducted by Macheka et al. (2013), other benefits given by the implementation of the ISO 22000 standard are the development of personnel skills, the upturn in sales, as well as the possibility of entrance on new markets. On the other hand, Escanciano and Santos-Vijande (2014b) state that this management standard can aid the company in forecasting market changes, increase its sales by utilizing the certification as an instrument, have access to valuable distribution chains and decrease the requirement for undertaking audits.

Even if the application of ISO 22000 leads the way to a long list of benefits, it also supposes some challenges. Karaman et al. (2012) state that the constraints that companies are exposed to when choosing to implement the ISO 22000 standard belong to three sources, namely difficulties imposed by the managerial level, technical aspects and even constraints arising from within the organization. According to Teixeira and Sampaio (2013), some of the drawbacks are represented by challenges in the product launching process at the introductory stage, legal norms, inexistent involvement and responsibility from the management part, hardships occurring in the understanding and application of the ISO standard's procedures, constraints imposed by time insufficiency, as well as the employees' skills and reluctance to change. Macheka et al. (2013) claim that other difficulties triggered by the implementation of ISO 22000 are an inappropriate infrastructure that cannot support the application process and the absence of financial funds and of food safety procedures. Furlan and Morozini (2013) found three major constraints limiting the dissemination and use of ISO 22000: it is not a well-known standard, many food companies are unaware of its potential and they also perceive high costs and hard time associated to the adoption. Similar findings are shared by Escanciano and Santos-Vijande (2014a), who underline the following constraints: unreasonable formality, the large amount of documents that are needed, the lack of standard recognition from the customers' part, communication issues at the company's level and the trouble with outside consultancy.

\section{Research methodology}

Prior research specifically aimed at analysing ISO 22000 implementation and its reasons, benefits and obstacles to ISO 22000 certification is very scarce. The purpose of the current study is to identify the key motivations that drive Romanian companies to adopt an ISO 
22000 model of food safety management. Also, the paper aims to analyse the main difficulties encountered by companies during the adoption process and the most influential benefits on companies overall satisfaction with ISO 22000. Based on the literature review carried out in the field we formulate the following research objectives:

- Identify the most prevalent motivations of the Romanian companies for adopting the ISO 22000 model of food safety management;

- Understand the key benefits of the ISO 22000 certification obtained by the Romanian companies;

- Understand the most significant difficulties that prevent the ISO 22000 standard implementation in Romanian companies;

- Identify which benefits have the highest impact on food safety improvement and business results in the sample companies.

The study includes a quantitative research which builds upon a questionnaire-based survey. The study population consisted of food companies which operate in Romania at different levels of the food supply chain. We used a simple random sampling to determine the sample size. This technique means that each unit that activates at different levels of the food supply chainis given an equal probability to be included in the sample (and has the same chance of selection), which is different from zero. The sample companies were sourced usingthe list of ISO 22000 certification entities active in Romania and accredited at national level, as well as well-known databases such as listafirme.ro and paginiaurii.ro. The sample included 327Romanian food companies distributed at all levels of the food chain, but mainly at the production level. The companies were contacted via e-mail, making use of the general contact available on their official websites. The accuracy of data regarding the official contact proved to be in many cases low and this led to a small number of valid responses collected.

Building upon related studies in the field (Teixeira and Sampaio, 2013; Escanciano and Santos-Vijande, 2014a, 2014b), a structured questionnaire was developed to identify the motivations, difficulties and benefits of the ISO 22000 implementation in Romanian food companies. The questionnaire included items related to specific problems encountered with ISO 22000 implementation and certification, its benefits achieved and reasons to pursue the process. It was organized into six sections: a general question about the achievement of the ISO 22000 certification, a question about certification motivations, a question about the effectiveness of certification, a question about difficulties to ISO 22000 adoption, a question about food safety methods in use, and a question regarding the company's and respondent's general profile. For each question the respondents had the option to add a new response that better reflected the reality from their organization. The survey was sent out to 327 food companies active in Romania, from all levels of the food supply chain, and mainly from the production area. The fieldwork period extended between August and mid-September 2017, the survey being hosted by Google Docs. The responses to the questionnaire were analysed using the Statistical Package for Social Sciences computer software (SPSS 23.0). The research is exploratory and employs two methods: factor analysis and multiple linear regression. Factor analysis is a statistical method, which serves to identify a set of latent components or factors that can be used to describe the relationships among sets of interrelated variables (Păunescu and Acatrinei, 2012), whilst multiple linear regression is a predictive 
analysis used to explain the relationship between one continuous dependent variable and two or more independent variables (Gelman and Hill, 2007).

The research hypotheses tested in the paper are defined as follows:

- $\mathrm{H}_{1}$ : Romanian companies manifest a strong desire of improvement of their food safety management and of differentiation among competitors.

- $\mathrm{H}_{2}$ : Qualification of employees, costs with food safety management system implementation and internal resistance to change are the major obstacles to ISO 22000 implementation in the Romanian companies.

- $\mathrm{H}_{3}$ : There is a significant positive correlation between the benefits perceived by the ISO 22000 certified companies and the overall improvement of their business results.

\section{Results and discussion}

\subsection{Sample companies profile}

The sample size consisted of 45 completed questionnaires in as many Romanian companies and 43 valid responses, with a response rate of $13.76 \%$. The low response rate can be explained by the lack of accuracy of the contact data available on companies' websites, the short period of time for the data collection process, or the lack of interest from the companies' side to participate in the research. An important constraint was also the companies' reluctance at sharing information about their identity. The respondents which participated in the survey were mainly responsible for food safety, quality manager or administrator of the company. The average seniority in the company of the respondents was 10 years. The profile of the sample companies is the following: (a) ISO 22000 certification: $71 \%$ certified and $29 \%$ not certified; (b) company size: $37 \%$ - large enterprises, $16 \%$ medium enterprises and 47\% - micro and small enterprises; (c) domains of activity: manufacturing, retail trade, wholesale, distribution and warehousing (figure no. 1).

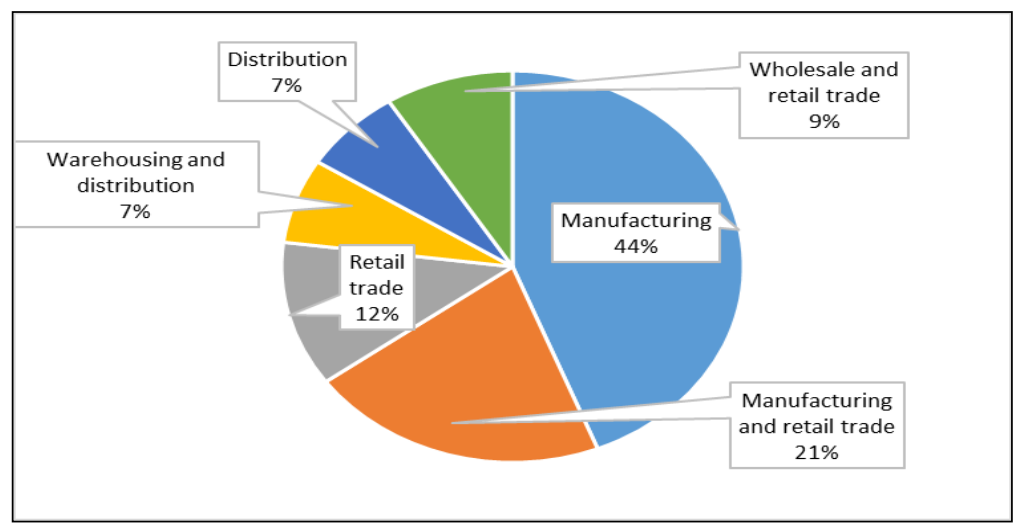

Figure no. 1: Domain of activity of the sample companies

Regarding the companies' preoccupations about ensuring and managing food safety in their internal operations and in the relationship with the customers, as they were self-reported by the surveyed companies, the following were noticed: $93 \%$ of the sample companies have a food recall plan, food handling is done according to the principles of HACCP and the 
companies keep records of monitoring data on food safety, whilst in $81 \%$ of the situations, companies make on regular basis microbiological and chemical testing of raw ingredients. On the other hand, only $56 \%$ of the sample companies ensure item level traceability, $67 \%$ of the companies conduct audits to their suppliers and/or co-packers, and in $74 \%$ of the situations food handlers are comprehensively trained.

\subsection{Analysis of motivations for adopting the ISO 22000 food safety management} system

Although many companies, especially the large ones, have implemented the ISO 22000 model of food safety management system, there are enough companies which are rather reluctant to implement it. The main reason behind that is the lack of information, the costs involved and the fear that the standard is too demanding in terms of administrative work.

Based on the literature review in the area we elaborated a list of 12 motivations $(\mathrm{M} 1 \div \mathrm{M} 12)$ for the implementation of the ISO 22000 model of food safety management. Using a fivepoint Likert scale ranging from 1 - not important to 5 - very important, respondents indicated how important each one of these motivations was for them in their decision to implement and certify their food safety management system to the ISO 22000 standard. As table no. 1 shows, all the motivations received a mean score above the middle point of the scale, meaning that all of them were important in the adoption process. The most salient reasons for adoption of the ISO 22000 food safety management system were guaranteeing the confidence of the consumers, improving corporate image and preventing food poisoning, followed by achieving market differentiation. Our findings are consistent with Escanciano and Santos-Vijande's (2014a) results who found three out of these motivations as the most highly valued reasons for implementation and certification based on ISO 22000.

Table no. 1: Descriptive statistics and correlation analysis of the motivations for implementing ISO 22000

\begin{tabular}{|l|c|c|c|c|c|c|c|c|c|c|c|c|c|c|}
\hline & M & SD & $\mathbf{1}$ & $\mathbf{2}$ & $\mathbf{3}$ & $\mathbf{4}$ & $\mathbf{5}$ & $\mathbf{6}$ & $\mathbf{7}$ & $\mathbf{8}$ & $\mathbf{9}$ & $\mathbf{1 0}$ & $\mathbf{1 1}$ & $\mathbf{1 2}$ \\
\hline M1 & 4.38 & 1.08 & 1 & .547 & .510 & .872 & .843 & .829 & .741 & .510 & .568 & .764 & .867 & .778 \\
M2 & 4.79 & 0.62 & & 1 & .550 & .563 & .709 & .410 & .314 & .255 & .406 & .583 & .664 & .398 \\
M3 & 4.72 & 0.46 & & & 1 & .573 & .464 & .620 & .525 & .482 & .696 & .495 & .556 & .573 \\
M4 & 4.21 & 1.05 & & & & 1 & .863 & .826 & .736 & .549 & .610 & .847 & .862 & .772 \\
M5 & 4.34 & 1.14 & & & & & 1 & .738 & .653 & .464 & .567 & .819 & .896 & .624 \\
M6 & 4.41 & 1.05 & & & & & & 1 & .874 & .744 & .817 & .896 & .873 & .826 \\
M7 & 4.21 & 1.15 & & & & & & & 1 & .593 & .679 & .775 & .789 & .736 \\
M8 & 4.17 & 1.36 & & & & & & & & 1 & .920 & .706 & .628 & .648 \\
M9 & 4.17 & 1.28 & & & & & & & & & 1 & .751 & .719 & .663 \\
M10 & 4.38 & 1.12 & & & & & & & & & & 1 & .901 & .755 \\
M11 & 4.59 & 1.09 & & & & & & & & & & & 1 & .831 \\
M12 & 4.21 & 1.05 & & & & & & & & & & & & 1 \\
\hline
\end{tabular}

To obtain further evidence on the ISO 22000 motivations, we employed an exploratory principal component analysis. The varimax with Kaizer normalization rotation method, using eigenvalue greater than one, revealed two distinctive motivational factors that accounted for $80.92 \%$ of the variance of the original variables (table no. 2). 
Table no. 2: Factor analysis of the motivations for implementing ISO 22000

\begin{tabular}{|l|c|c|}
\hline & Factor 1 & Factor 2 \\
\hline M8 - Involvement and commitment of the food chain in the product & .916 & \\
safety & .902 & \\
M9 - Continuous improvement of the employees'skills & .814 & \\
M6 - Market differentiation & .727 & \\
M7 - Access to new markets & .708 & \\
M12 - Improvement of the relationship with the society & .667 & \\
M10 - Salubrity and food safety improvement & .554 & \\
M3 - Corporate image improvement & & .876 \\
M5 - Legal requirements & & .841 \\
M2 - To guarantee the confidence of the consumers & & .766 \\
M11 - Prevent food poisoning & & .765 \\
M1 - Cost reduction & & .763 \\
M4 - Customer requirement & 7.549 & 9.161 \\
Eigenvalue & 71.245 & 80.921 \\
Proportion of the variance explained & 71.245 & \\
Cumulative proportion of the variance explained & &
\end{tabular}

The eigenvalue represents the total of variance explained by one factor. Any factor that has an eigenvalue less than one does not have enough total variance explained to represent a unique factor and it is, therefore, disregarded. The scale for motivations was tested for normality and reliability using the Bartlett test of sphericity. The Kaiser-Meyer-Olkin (KMO) measure of sampling adequacy was 0.815 (close to 1.0) and the Bartlett test was 438.165 with a significant level of $\mathrm{p}<0.0001$. These values reinforced that the data can be reliably tested using factor analysis.

Factor 1 (Cronbach's alpha=0.937) includes seven motivations, which are variables suggesting a strong desire for overall improvement (improvements of food safety, of employees' skills, of corporate image, and of the relationship with society) and differentiation (on old and new markets). Factor 2 (Cronbach's alpha=0.942) includes five motivations, which are variables linked with the organization desire to comply with requirements (legal and customer's requirements), reduce costs, prevent food poisoning and enhance consumers' confidence. The results of the factor analysis of the motivations of Romanian companies for adopting a food safety management system based on the ISO 22000 standard confirm the first research hypothesis $\mathrm{H} 1$.

\subsection{Analysis of the difficulties in the effective implementation of the ISO 22000 food safety management system}

Many studies on the subject refer to various obstacles and constraints faced by the companies that undertook the ISO 22000 certification process. From the literature review we identified 11 difficulties (D1 $\div$ D11) that may act as potential obstacles in the implementation process of the ISO 22000 model of food safety management system. Respondents indicated on a five-point Likert scale the extent to which each obstacle had been relevant to their organization (from 1 - not significant at all to 5 - very significant). Table no. 3 presents the means and standard deviations of the respondents' valuations of the extent to which their companies had experienced these difficulties during the ISO 22000 adoption process. Table shows that there are several more prevalent difficulties with a mean score above the middle point of the scale, namely: employees' qualification, costs associated with the food safety management system implementation and legal 
requirements, followed closely by internal resistance to change, difficulties that companies should consider more carefully in the process of the ISO 22000 standard adoption.

Table no. 3: Descriptive statistics and correlation analysis of the difficulties to implementing ISO 22000

\begin{tabular}{|l|c|c|c|c|c|c|c|c|c|c|c|c|c|}
\hline & M & SD & $\mathbf{1}$ & $\mathbf{2}$ & $\mathbf{3}$ & $\mathbf{4}$ & $\mathbf{5}$ & $\mathbf{6}$ & $\mathbf{7}$ & $\mathbf{8}$ & $\mathbf{9}$ & $\mathbf{1 0}$ & $\mathbf{1 1}$ \\
\hline D1 & 2.97 & 1.401 & 1 & .507 & .029 & .428 & .447 & .325 & .362 & .434 & .531 & .612 & .539 \\
D2 & 3.17 & 1.416 & & 1 & .324 & .196 & .416 & .435 & .456 & .194 & .239 & .642 & .622 \\
D3 & 3.41 & 1.240 & & & 1 & .515 & .431 & .287 & .281 & .290 & .317 & .313 & .221 \\
D4 & 2.76 & 1.057 & & & & 1 & .563 & .440 & .449 & .577 & .648 & .381 & .312 \\
D5 & 2.52 & 1.056 & & & & & 1 & .719 & .731 & .716 & .751 & .358 & .624 \\
D6 & 2.38 & 1.049 & & & & & & 1 & .984 & .480 & .509 & .237 & .629 \\
D7 & 2.34 & 1.010 & & & & & & & 1 & .445 & .479 & .273 & .648 \\
D8 & 2.34 & 1.078 & & & & & & & & 1 & .855 & .498 & .287 \\
D9 & 2.14 & 1.302 & & & & & & & & & 1 & .537 & .442 \\
D10 & 3.14 & 1.505 & & & & & & & & & & 1 & .459 \\
D11 & 2.76 & 1.550 & & & & & & & & & & & 1 \\
\hline
\end{tabular}

Similarly to the procedure used in the motivation case, to obtain a further evidence on the obstacles to the ISO 22000 food management system adoption, the 11 difficulties were subjected to an exploratory factor analysis. The KMO measure of sampling adequacy was 0.63 and the Bartlett test result was 276.327 with a significance level of $p<0.0001$. These values suggest that the data could reliably be tested using factor analysis. The result of the varimax with Kaizer normalization rotation method using eigenvalue greater than one was the identification of three difficulty factors that accounted for $76.76 \%$ of the variance of the original variables (table no. 4).

Table no. 4: Factor analysis of the difficulties to implementing ISO 22000

\begin{tabular}{|c|c|c|c|}
\hline & Factor 1 & Factor 2 & Factor 3 \\
\hline D8 - Lack of employees' motivation and involvement & .862 & & \\
\hline D9 - Lack of top management commitment and involvement & .851 & & \\
\hline D4 - Reduction of the employees' time to make other tasks & .790 & & \\
\hline D5 - Time limitations & .645 & & \\
\hline D3 - Employees' qualification & .495 & & \\
\hline D7 - Difficulties in the comprehension and interpretation of & & 906 & \\
\hline D6 - Difficulties in the use of the food safety management & & & \\
\hline system tools and methodologies & & .902 & \\
\hline D11 - More difficulties for the introduction of new products & & .667 & \\
\hline D10 - Legal requirements & & & .834 \\
\hline D2 - Food safety management system implementation costs & & & .786 \\
\hline D1 - Internal resistance to change & & & .763 \\
\hline Eigenvalue & 5.726 & 1.402 & 1.316 \\
\hline Proportion of the variance explained & 52.058 & 12.744 & 11.959 \\
\hline Cumulative proportion of the variance explained & 52.058 & 64.803 & 76.762 \\
\hline
\end{tabular}

Factor 1 (Cronbach's alpha=0.862) includes five difficulties, which are variables linked with the provision of the resources in terms of motivation, involvement and qualification of employees, but also necessary time. Factor 2 (Cronbach's alpha $=0.865$ ) includes three difficulties, which are variables suggesting constraints due to the comprehension and interpretation of the standard requirements, the use of the food safety management system tools and methodologies and the introduction of new products. Factor 3 (Cronbach's 
alpha $=0.811$ ) includes three mixed difficulties, which refer to legal requirements, food safety management system implementation costs and internal resistance to change. Despite the many difficulties, both material and organizational, that sample companies experienced in implementing ISO 22000, taking into consideration the benefits acknowledged, the overall satisfaction is high. The results of the factor analysis of the difficulties experienced by Romanian companies in the implementation of the ISO 22000 model of food safety management confirm the second research hypothesis $\mathrm{H} 2$.

\subsection{Analysis of benefits of the ISO 22000 food safety management system certification}

ISO 22000 certified companies managed to achieve various benefits as a result of this process. From the literature review we listed 16 benefits $(\mathrm{B} 1 \div \mathrm{B} 16)$, which were acknowledged by the companies with ISO 22000 certification. Using a five-point Likert scale ranging from 1 - not important to 5 - very important, respondents scored the extent to which their companies obtained these benefits through implementation and certification based on ISO 22000. Table no. 5 shows that all the benefits received a mean score above the middle point of the scale, meaning that all of them were obtained through the ISO 22000 standard certification. The key benefits obtained by our sample companies were food safety improvement, reduction of illness and other risks arising from food, improvement of consumers' confidence, improvement of customers and stakeholders' satisfaction, followed by improvement of sales volumes. Similar findings were also obtained by Escanciano and Santos-Vijande (2014b) who mentioned better control of food hazards, continuous improvement of food safety and increased customer confidence among the benefits of ISO 22000 certification that most contribute to the fulfilment of the companies'objectives.

Table no. 5: Descriptive statistics and correlation analysis of the benefits of implementing ISO 22000

\begin{tabular}{|c|c|c|c|c|c|c|c|c|c|c|c|c|c|c|c|c|c|c|}
\hline & M & SD & 1 & 2 & 3 & 4 & 5 & 6 & 7 & 8 & 9 & 10 & 11 & 12 & 13 & 14 & 15 & 16 \\
\hline B1 & 4.34 & .89 & 1 & .74 & .43 & .533 & .336 & .473 & .588 & .665 & .824 & .600 & .647 & .302 & .531 & .351 & .256 & .297 \\
\hline B2 & 4.55 & .82 & & 5 & 7 & .616 & .355 & .497 & .610 & .511 & .654 & .462 & .640 & .429 & .478 & .478 & .259 & .369 \\
\hline B3 & 4.28 & .84 & & 1 & .33 & .737 & .315 & .491 & .486 & .558 & .385 & .456 & .658 & .446 & .576 & .444 & .460 & .398 \\
\hline B4 & 4.55 & .78 & & & 8 & 1 & .375 & .525 & .645 & .438 & .511 & .564 & .846 & .531 & .725 & .627 & .496 & .467 \\
\hline B5 & 4.69 & .60 & & & 1 & & 1 & .642 & .658 & .333 & .405 & .755 & .382 & .496 & .629 & .567 & .357 & .682 \\
\hline B6 & 4.38 & .77 & & & & & & 1 & .579 & .672 & .767 & .718 & .424 & .577 & .794 & .513 & .376 & .554 \\
\hline B7 & 4.28 & 1.03 & & & & & & & 1 & .416 & .519 & .744 & .622 & .805 & .748 & .888 & .713 & .589 \\
\hline B8 & 3.90 & .90 & & & & & & & & 1 & .757 & .497 & .397 & .426 & .650 & .363 & .455 & .433 \\
\hline B9 & 4.10 & 1.01 & & & & & & & & & 1 & .668 & .566 & .371 & .668 & .308 & .216 & .364 \\
\hline B10 & 4.38 & 1.20 & & & & & & & & & & 1 & .675 & .647 & .866 & .673 & .472 & .582 \\
\hline B11 & 4.69 & .80 & & & & & & & & & & & 1 & .559 & .720 & .583 & .397 & .398 \\
\hline B12 & 4.21 & 1.17 & & & & & & & & & & & & 1 & .808 & .882 & .728 & .523 \\
\hline B13 & 4.14 & 1.24 & & & & & & & & & & & & & 1 & .803 & .674 & .646 \\
\hline B14 & 4.41 & 1.11 & & & & & & & & & & & & & & 1 & .815 & .802 \\
\hline B15 & 4.24 & 1.02 & & & & & & & & & & & & & & & & .611 \\
\hline B16 & 3.62 & 1.17 & & & & & & & & & & & & & & & & \\
\hline
\end{tabular}

The ISO 22000 benefits made further the subject of an exploratory factor analysis, to collect new evidence. A varimax-rotated factor analysis using eigenvalue greater than one revealed three distinctive benefit factors that accounted for $77.64 \%$ of the variance of the original variables (table no. 6). The reliability of the benefit-scale was also tested using the Bartlett test of sphericity and the Kaiser-Meyer-Olkin. The Bartlett test was 552.195 with a 
significant level of $\mathrm{p}<0.0001$. The KMO measure of sampling adequacy was 0.619 , these values suggesting again that the data can be reliably tested using factor analysis.

Table no. 6: Factor analysis of the benefits to implementing ISO 22000

\begin{tabular}{|l|c|c|c|}
\hline & Factor 1 & Factor 2 & Factor 3 \\
\hline B5 - Food safety improvement & .798 & & \\
B14 - Sales volume improvement & .762 & & \\
B16 - Increase of the products shelf time & .745 & & \\
B12 - Access to new markets & .731 & & \\
B13 - Improvement of the relationship with the society & .705 & & \\
B7 - Business results improvement & .685 & & \\
B10 - Reduction or elimination of the non-safety products & .683 & & \\
B15 - Production costs reduction & .649 & & \\
B9 - Continuous improvement of the employees' skills & & .917 & \\
B1 - The improvement of food safety methodologies and & & .823 & \\
practices & & .715 & \\
B8 - Employees motivation improvement & & .652 & \\
B2 - Improvement of customers and stakeholders & & .647 & \\
satisfaction & & & .785 \\
B6 - Corporate image improvement & & .758 \\
B4 - Improvement of consumers' confidence & & .668 \\
B11 - Reducing illness and other risks arising from food & & & 1.215 \\
B3 - Reduce number of complaints & 9.359 & 1.849 & 77.643 \\
Eigenvalue & 58.492 & 11.557 & \\
Proportion of the variance explained & 58.492 & 70.048 & \\
Cumulative proportion of the variance explained & & \\
\hline
\end{tabular}

Factor 1 (Cronbach's alpha=0.940) includes eight benefits, which are variables linked with the economic efficiency and business results achieved by the company, such as: sales volume improvement, production costs reduction, business results improvement, access to new markets and improvement of the relationship with the society. Also, the first factor includes variables suggesting improvements of the quality and safety of the food products: food safety improvement, increase of the products shelf-time and reduction of non-safety products. Factor 2 (Cronbach's alpha=0.906) includes five benefits, which are variables suggesting improvements achieved in internal operations, like improvements of employees 'skills and motivation or of food safety methodologies, but also improvements of the relationship with stakeholders and of the overall corporate image. Factor 3 (Cronbach's alpha $=0.897$ ) includes three benefits, which are variables suggesting enhanced confidence among customers nurtured also by the reduced illness and reduced number of complaints.

\subsection{Regression analysis of the benefits of implementing ISO 22000 on business results} improvement

In order to determine which of the benefits had the highest impact on the companies' overall business results improvement, data were subjected to a multiple linear regression, taking the business results improvement as the dependent variable, and the perceived benefits of ISO 22000 certification as the independent (or explanatory) variables (table no. 7).

The linear regression model assumes that there is a linear relationship between the dependent variable and each predictor. The standardized coefficients (Beta) determine the relative importance of the significant predictors. Thus, following a t distribution, results indicate that the linear correlation between the business results improvement and the 
certified companies' perceived benefits was statistically significant in the following cases: sales volume improvement, access to new markets, continuous improvement of the employees' skills, food safety improvement, the improvement of food safety methodologies and practices, improvement of consumers' confidence, production costs reduction, and reduction or elimination of the non-safety products (table no. 7). Table no. 7 also reports a significant $F$ statistic (70.841) as an indicator of the statistical significance of the regression equation. Also, $97 \%$ (adjusted $\mathrm{R}^{2}$ ) of the variation in business results regarding food safety improvement expectations are explained by the model.

Table no. 7: Regression analysis between business results improvement and ISO 22000 benefits

\begin{tabular}{|c|c|c|c|c|c|}
\hline & \multicolumn{2}{|c|}{$\begin{array}{c}\text { Unstandardized } \\
\text { Coefficients }\end{array}$} & \multirow{2}{*}{$\begin{array}{c}\begin{array}{c}\text { Standardized } \\
\text { Coefficients }\end{array} \\
\text { Beta } \\
\end{array}$} & \multirow{2}{*}{$\mathbf{t}$} & \multirow{2}{*}{ Sig. } \\
\hline & B & Std. Error & & & \\
\hline \multirow{2}{*}{$\begin{array}{c}\text { (Constant) } \\
\text { B1 }\end{array}$} & \multirow{16}{*}{$\begin{array}{c}-2.685 \\
.294 \\
-.209 \\
.064 \\
.428 \\
.387 \\
-.030 \\
-.229 \\
.518 \\
.186 \\
-.224 \\
.374 \\
-.805 \\
.597 \\
.191 \\
.013\end{array}$} & .678 & & -3.961 & .002 \\
\hline & & .115 & .256 & 2.550 & .024 \\
\hline B2 & & .154 & -.168 & -1.358 & .198 \\
\hline $\begin{array}{l}\text { B3 } \\
\text { B4 }\end{array}$ & & .149 & .052 & .431 & .674 \\
\hline B5 & & .145 & .325 & 2.957 & .011 \\
\hline B6 & & .112 & .226 & 3.456 & .004 \\
\hline B8 & & .218 & -.022 & -.136 & .894 \\
\hline B9 & & .142 & -.200 & -1.621 & .129 \\
\hline B10 & & .147 & .508 & 3.534 & .004 \\
\hline B12 & & .093 & .217 & 1.998 & .067 \\
\hline B13 & & .198 & -.175 & -1.130 & .279 \\
\hline B14 & & .079 & .427 & 4.733 & .000 \\
\hline B15 & & .242 & -.973 & -3.324 & .005 \\
\hline B16 & & .116 & .648 & 5.146 & .000 \\
\hline & & .068 & .190 & 2.810 & .015 \\
\hline & & .044 & .015 & .294 & .774 \\
\hline $\begin{array}{l}\text { F } \\
\text { R Square } \\
\text { Adjusted R } \\
\text { Square } \\
\end{array}$ & $\begin{array}{r}70.841 \\
.988 \\
974\end{array}$ & & & & \\
\hline
\end{tabular}

The results of the regression analysis of the benefits of implementing the ISO 22000 model of food safety management on the business results improvement for the sample Romanian companies confirm the last research hypothesis $\mathrm{H} 3$, meaning that there is a significant positive correlation between the benefits perceived by the ISO 22000 certified companies and the overall improvement of their business results.

\section{Conclusions}

The assurance of food safety is obligatory for the protection of public health. Implementation of the ISO 22000 food safety management system is a fundamental approach to ensure the safety of the food supply, providing a systematic procedure for the identification, evaluation and control of hazards and risks in each process. 
The paper identifies the key motivations that drive sample Romanian companies to adopt an ISO 22000 model of food safety management. The most prevalent reasons for the adoption of ISO 22000 were guaranteeing the confidence of the consumers, improving corporate image and preventing food poisoning, followed by achieving market differentiation. Also, the paper analyses the main difficulties encountered by sample Romanian companies during the ISO 22000 implementation process and the most influential benefits on companies overall satisfaction with ISO 22000. The more prevalent difficulties were employees' qualification, costs associated with food safety management system implementation and legal requirements, followed closely by internal resistance to change. This information is very useful for the food companies which are on the step of implementing the ISO 22000 system, as they have to treat these potential difficulties with more care and consideration.

The key benefits obtained by our sample companies were food safety improvement (and safer products), reduction of illness and other risks arising from food, improvement of consumers' confidence, improvement of customers and stakeholders' satisfaction, followed by improvement of sales volumes. The regression analysis between business results improvement and perceived benefits of ISO 22000 certification concluded that the benefits which bring the most valuable impact on improvement of food safety and further of business results were: sales volume improvement, access to new markets, continuous improvement of the employees' skills, obtaining safer food products, improvement of food safety methodologies and practices, improvement of consumers' confidence, production costs reduction, and reduction or elimination of the non-safety products.

Like the other researches, this study is not without limitations. The main limitation is given by the size of the sample, which, being so low, didn't allow for meaningful comparisons between the ISO 22000 certified large, medium and small companies. However, the results proved to be statistically significant for sample companies and, therefore, highly reliable for those food companies interested to learn more about the challenges of implementing the ISO 22000 model of food safety management system.

Future research can further build on our results and, using a larger sample, explore possibilities to design future strategies for managing the food safety, differentiated among food companies by size and sector of activity.

\section{Acknowledgement}

Special thanks are extended to the editor of the journal and the reviewers of the paper for their insightful comments and constructive recommendations, which made possible the improvement and finalization of this article.

\section{References}

Afoakwa, E.O., Mensah-Brown, H., Crentsil, G.K., Frimpong, K. and Asante, F., 2013. Application of ISO 22000 in comparison with HACCP on industrial processing of milk chocolate. International Food Research Journal, 20(4), pp.1771-1781.

Ahmed, T.A., Saeed, S.A.M. and Hussien, H.A., 2013. Evaluation of poultry meat safety based on ISO 22000 as food safety management system. Pakistan Journal of Nutrition, 12(2), pp.121-129.

Arvanitoyannis, I.S. ed., 2009. HACCP and ISO 22000: Application to foods of animal origin. Oxford: Wiley-Blackwell. 
Bilalis, D., Stathis, I., Konstantas, A. and Patsiali, S., 2009. Comparison between HACCPP and ISO 22000 in Greek organic food sector. Journal of Food, Agriculture \&Environment, 7(2), pp.237-242.

Escanciano, C. and Santos-Vijande, M.L., 2014a. Reasons and constraints to implementing an ISO 22000 food safety management system: Evidence from Spain. Food Control, 40, pp.50-57.

Escanciano, C. and Santos-Vijande, M.L., 2014b. Implementation of ISO-22000 in Spain: obstacles and key benefits. British Food Journal, 116(10), pp.1581-1599.

Faergemand, J., 2008. The ISO 22000 series global standards for safe food supply chains. ISO Management Systems, 8(3), pp.4-7.

Furlan, M. and Morozini, J.F., 2013. Implementation of ISO 22000 in a storage unit of a grain cooperative from the midwest region of Parana. Custos e Agronegocio Online, 9(4), pp.232-256.

Gelman, G. and Hill, J., 2007. Data analysis using regression and multilevel/hierarchical models. Cambridge: Cambridge University Press.

Herath, D. and Henson, S., 2006. Does Canada need mandatory HACCP? Evidence from the Ontario food processing sector. Canadian Journal of Agricultural Economics, 54(4), pp.443-459.

International Standards Office - ISO, 2005. ISO 22000Food safety management systems Requirements for any organization in the food chain. Geneva: ISO.

Karaman, A.D., Cobanoglu, F., Tunalioglu, R. and Ova, G., 2012. Barriers and benefits of the implementation of food safety management systems among the Turkish dairy industry: a case study. Food Control, 25(2), pp.732-739.

Keran, H., Dzevdetbegovic, M., Ahmetovic, N., Sehovic, A. and Salkic, M., 2008. Implementation of the food safety management according to ISO 22000:2005 in Menprom, Meat Company in Tuzla, B\&H. In: The Society of the Food Technologists, Biotechnologists and Nutritionists, 2008 Joint Central European Congres. Cavtat, Croatia, 15-17 May 2008. Zagreb: The Society of the Food Technologists, Biotechnologists and Nutritionists. Ch2, pp. 83-90.

Kok, M.S., 2009. Application of food safety management systems (ISO 22000/HACCP) in the Turkish poultry industry: A comparison based on enterprise size. Journal of Food Protection, 72(10), pp.2221-2225.

Lokunarangodage, C.V.K., Wickramasinghe, I. and Ranaweera, K.K.D.S., 2016. Review of ISO 22000:2005, Structural synchronization and ability to deliver food safety with suggestions for improvements. Journal of Tea Science Research, 5(12), pp.1-12.

Macheka, L., Manditsera, F.A., Ngadze, R.T., Mubaiwa, J. and Nyanga, L.K., 2013. Barriers, benefits and motivation factors for the implementation of food safety management system in the food sector in Harare Province, Zimbabwe. Food Control, 34, pp.126-131

Mamalis, S., Kafetzopoulos, D.P. and Aggelopoulos, S., 2009. The new food safety standard ISO 22000. Assessment, comparison and correlation with HACCP and ISO 9000:2000. The practical implementation in victual business. In: The 113th EAEE Seminar A Resilient European Food Industry and Food Chain in a Challenging World. Crete, Greece, 3-6 September 2009. [online] Available at: <http://ageconsearch. umn.edu/bitstream/ 58088/2/Mamalis.pdf> [Accessed 2 September 2017]. 
Massoud, M.A., Fayad, R., El-Fadel, M. and Kamleh, R., 2010. Drivers, barriers and incentives to implementing environmental management systems in the food industry: A case of Lebanon. Journal of Cleaner Production, 18(3), pp.200-209.

Mensah, L.D. and Julien, D., 2011. Implementation of food safety management systems in the UK. Food Control, 28(8), pp.1216-1225.

Păunescu, C., 2017. The importance of certification of organizations' management systems to ISO standards. Quality - Access to Success, 17(153), pp.108-110.

Păunescu, C. and Acatrinei, C., 2012. Managing maturity in process-based improvement organizations: A perspective of the Romanian companies. Journal of Business Economics and Management, 13(2), pp.223-241.

Sheps, I., 2007. ISO 22000: The new international standard on food safety - A comparison to HACCP (Danish Standard DS 3027,2. edition). Journal of Environmental Protection and Ecology, 8(4) pp.940-949.

Silva, M.M., Fonseca, L.M. and Sousa, S.D., 2016. The Impact of ISO 9001:2015 on ISO 22000 and Food Safety Management Systems (FSMS). Quality - Access to Success, 17(152), pp.81-85.

Smith, D., Jackson-Smith, T. and Politowski, R., 2007. ISO 22000 Food safety: guidance and workbook for the manufacturing industry. London: BSI.

Soares, N.F., Vicente, A.A. and Martins, C.M.A., 2016. Food safety in the seafood industry: A practical guide for ISO 22000 and FSSC 22000 Implementation. 1st ed. Chichester: John Wiley\&Sons.

Soman, R. and Raman, M., 2016. HACCP system - hazard analysis and assessment, based on ISO 22000:2005 methodology. Food Control, 69, pp.191-195.

Stranieri, S., Cavaliere, A. and Banterle, A., 2017. Do motivations affect different voluntary traceability schemes? An empirical analysis among food manufacturers. Food Control, 80, pp.187-196.

Teixeira, S. and Sampaio, P., 2013. Food safety management system implementation and certification: survey results. Total Quality Management \& Business Excellence, 24(34), pp.275-293.

Uyar, M.F., Dikmen, D., Kizil, M., Tengilimoglu, M., Bilici, S., Tavasli, A. and Sağlam, F., 2012. Patients' satisfaction level before and after HACCP/ISO 22000 implementation to food and food service in university hospital, Ankara, Turkey. HealthMED, 6(2), pp. 348-351.

Weyandt, A.J., Reis da Costab, S.R., Nunesc, M.L. and Gaspara, A., 2011. Environmental \& food safety management systems, according to ISO 14001 \& ISO 22000 in fish processing plants: experiences, critical factors \& possible future strategies. Procedia Food Science, 1, pp.1901-1906.

Wognum, N., Bremmers, H., Trienekens, J. and Bloemhof-Ruwaard, J., 2011. Systems for sustainability and transparency of food supply chains-Current status and challenges. Advanced Engineering Informatics, 25(1), pp.65-76.

Zorpas, A.A. and Tzia, N., 2008. The implementation of a new ISO 22000 in the Cyprus olive oil industry. WIT Transactions on Information and Communication Technologies, 39, pp.261-274. 